\title{
PELATIHAN DAN PENDAMPINGAN PENGGUNAAN CANVA DI DESA GUMBRIH, KECAMATAN PEKUTATAN, KABUPATEN JEMBRANA
}

\author{
Gerson Feoh ${ }^{1}$, I Wayan Ruspendi Junaedi ${ }^{2}$, I Gusti Bagus Rai Utama ${ }^{3}$ \\ ${ }^{1}$ Program Studi Teknik Informatika, Universitas Dhyana Pura \\ ${ }^{2}$ Program Studi Manajemen, Universitas Dhyana Pura \\ ${ }^{3}$ Program Studi Manjemen Perhotelan, Universitas Dhyana Pura
}

gerson.feoh@undhirabali.ac.id, ruspendijunaedi@undhirabali.ac.id, raiutama@undhirabali.ac.id

\begin{abstract}
Abstrak
Badan Usaha Milik Desa (BUMDES) Catu Graha Mandiri Gumbrih memiliki potensi sumber daya alam dan hasil produk berupa kopi yang potensial namun dalam pemasaran memiliki kesulitan dalam memasarkan produk mereka secara digital. Untuk itu, melalui program kemitraan masyarakat, tim dari Universitas Dhyana Pura memberikan pelatihan dan pendampingan dalam meningkatkan kualitas promosi dan pemasaran produk usahausaha BUMDES Catu Graha Mandiri, Gumbrih.dalam menggunakan aplikasi Canva via smartphone peserta. Metode yang digunakan selama pelatihan dan pendampingan, setiap peserta diberikan form kuisioner awal (pratest) untuk mengetahui kemampuan awal peserta. Langkah selanjutnya adalah memberikan gambaran secara umum fitur dan hasil yang dapat dihasilkan dengan menggunakan aplikasi Canva, kemudian meminta para peserta melakukan secara mandiri dalam mempromosikan produk usaha mereka. Diakhir pelatihan dan pendampingan, peserta diberikan form kuisioer akhir (posttest) untuk mengetahui pengukuran kemampuan para peserta setelah diberikan pelatihan dan pendampingan menggunakan Canva. Hasil dari pelatihan dan pendampingan yang intensif, tergambar dalam melalui data pada kuisioner yang disebarkan sebelum (pra test) dan sesudah (post test) Program Kemitraan ini, dimana ada peningkatan kemampuan pengetahuan pada 30 peserta pelatihan dan pendampingan dari rata-rata skor 60,7 menjadi rata-rata skor 97 sehingga dapat disimpulkan pengetahuan dari pengelola usaha-usaha BUMDES Catu Graha Mandiri Gumbrih terjadi peningkatan pemahaman mitra pengabdian. Dampaknya sangat positif, dimana para pengelola usaha-usaha BUMDES Catu Graha Mandiri Gumbrih, dapat secara mandiri mempromosikan usaha nya melalui media sosial, baik berupa logo, sampai dengan video kreatif yang dihasilkan melalui aplikasi Canva
\end{abstract}

Kata Kunci : Canva, PKM UNDHIRA, Pemasaran Digital, BUMDES Catu Graha Mandiri

\section{PENDAHULUAN}

BUMDES Catu Graha Mandiri berbeda dengan BUMDES lainnya yang ada di Bali. BUMDES yang telah terbentuk perlu dilatih dalam bidang iptek untuk memetakan, mengembangkan, dan mengatur berbagai potensi alam dan budaya yang dimiliki oleh dua Subak yang terdapat di Desa Gumbrih dengan ciri khasnya masing-masing. Setiap anggota kelompok usaha mampu 
menerapkan teknik promosi dengan menggunakan media social seperti facebook, twitter, WA, Line, dan sejenisnya. BUMDES Catu Graha Mandiri Desa Gumbrih ini belum memiliki profil yang lengkap tentang berbagai usaha yang terkait dengan kepariwisataan dan aspek lain sebagai daya tarik wisata, seperti subak abian dan subak sawah. Subak Abian dan subak sawah yang memiliki objek wisata tracking (ATV), Subak tersebut yang memiliki objek wisata. Subak Pangkung Srangsang yang memiliki objek wisata terasering padi, Subak Abian yang memiliki objek wisata Eco (kelapa, Coklat, pisang, kopi, aneka buah, aneka sayur, aneka Bunga, aneka tanaman upacara, anake tanaman obat dan tanaman langka). Sehingga diperlukan Pelatihan promosi pemasaran usaha produk BUMDES Catu Graha Mandiri Desa Gumbrih ini kepada anggota atau Kelompok Masyarakat (POKMAS) yang ada desa Gumbrih tersebut untuk meningkatkan pemasukan (penerimaan) BUMDES Catu Graha Mandiri Desa Gumbrih ini. Manfaat melalui melalui pelatihan dan pendampingan ini yaitu bagi pengelola usaha-usaha BUMDES Catu Graha Mandiri Desa Gumbrih dapat membuat desain produk dan memasarkan nya secara digital secara mandiri, sehingga sumber daya alam dan produk-produk usaha, salah satunya adalah kopi dapat diperkenalkan ke masyarakat luas secara modern baik desain kemasan, logo, sampai pemasaran secara digital.

Gambaran lengkap Kantor Desa Wisata Gumbrih dan usaha-usaha yang saat ini dikelola BUMDES Catu Graha Mandiri Gumbrih dapat dilihat pada gambar 1, gambar 2, dan gambar 3.

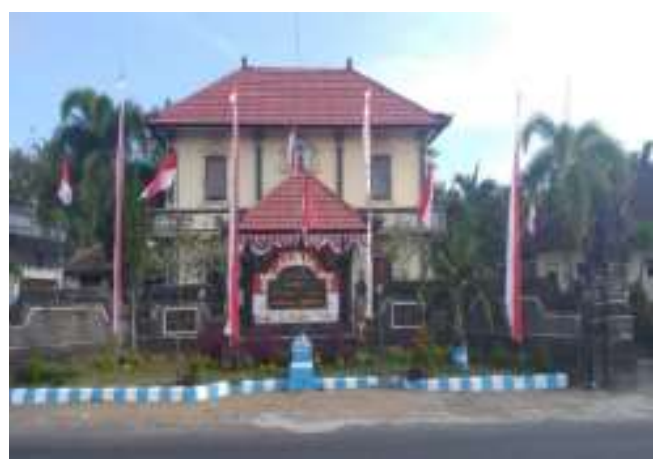

Gam bar 1.

Kant or

Desa Wisa ta Gum brih

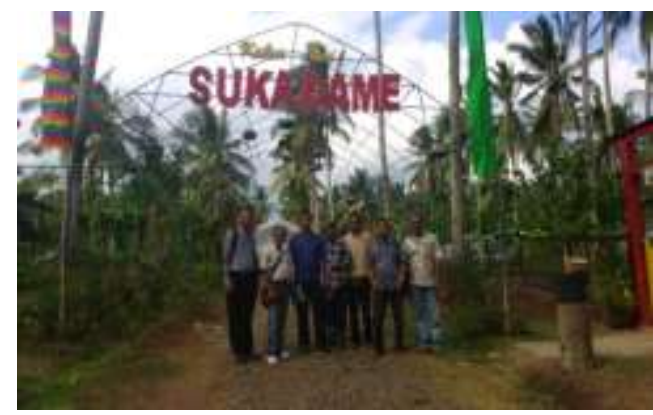

Gambar 2. Petani Organik Sukadame

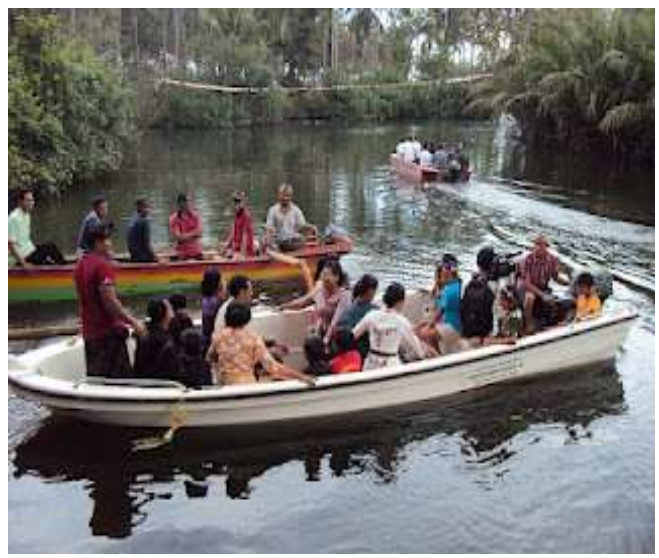

Gambar 3. Wisata Tirta

\section{METODE}

Metode yang digunakan selama pelatihan dan pendampingan diawali dengan penyebaran kusioner pratest untuk dapat mengetahui kemampuan awal para pengelola usaha-usaha BUMDES Catu Graha Mandiri Desa Gumbrih. Dilanjutkan dengan pemberikan materi secara umum, demonstrasi dalam menggunakan aplikasi, dan pendampingan bagi para peserta yang secara mandiri membuat berbagai macam bentuk dalam memasarkan produknya mulai dari desain logo sampai dengan desain pemasaran secara digital. Setelah pelatihan dan pendampingan, pengelola usaha-usaha BUMDES Catu Graha Mandiri Desa Gumbrih diberikan kembali kusioner posttest untuk dapat mengetahui perkembangan pengetahuan para peserta. Ada beberapa tahapan-tapan dalam 
pelatihan dan pendampingan pengelola usaha-usaha BUMDES Catu Graha Mandiri Desa Gumbrih ini.

Tahap Pelatihan

Memberikan pendampingan, penyuluhan, dan pelatihan dalam pemasaran produk yang tergabung dalam BUMDES Catu Graha Mandiri secara benar dengan menggunakan internet, media cetak dan media sosial. Pemasaran menjadi kunci utama dalam mempromosikan dan menjual produk BUMDES Catu Graha Mandiri. Dengan promosi yang benar maka dapat meningkatkan omzet penjualan serta mengembangkan usaha ini demi kesejahteraan anggota kelompok usaha BUMDES Catu Graha Mandiri ini maupun masyarakat di sekitarnya. Disamping itu juga pembuatan media cetak yang memungkinkan mempromosikan usahausaha seperti usaha dagang, simpan pinjam, rekreasi, aktivitas wisata, pengelolaan keuangan dan sejenisnya. Pelatihan ini dilakukan oleh tim pelaksana PKM yang dibantu oleh mahasiswa Teknik Informatika Universitas Dhyana Pura. Tim membuatkan spanduk usaha (sebagai alat promosi) untuk mengatasi masalah pemasaran usaha usaha tersebut. Program ini diharapkan mampu meningkatkan pemasukan BUMDES Catu Graha Mandiri.

\section{Tahap Pendampingan}

Setelah selesai tahap pelatihan, maka para pengelola usaha BUMDES Catu Graha Mandiri mampu mengelola usaha secara mandiri. Tim pelaksana PKM dan pakar akan mendampingi setiap anggota kelompok selama beberapa hari, sehingga mereka dapat menanyakan apabila mengalami kesulitan selama ujicoba kegiatan tersebut. Pendampingan ini juga bertujuan untuk mengingatkan anggota kelompok jika melakukan kesalahan dalam ujicoba, sehingga tidak berbeda dengan materi pelatihan sebelumnya. Target yang hendak dicapai dari pendampingan ini adalah agar semua anggota kelompok dapat mengelola usaha mereka secara mandiri serta mampu mengembangkan potensi usahanya yang pada akhirnya meningkatkan Penerimaan Asli Desa (PAD) Gumbrih.

\section{Tahap Monitoring PKM}

Tahap monitoring dilakukan oleh tim pelaksana, Kepala Desa Gumbrih, dan tim LP2M Universitas Dhyana Pura. Pada tahap monitoring ini semua kegiatan harus bisa terlihat peningkatannya, mulai dari tahap pelatihan, pendampingan, dan hasil yang sudah diperoleh oleh pengelola BUMDES Catu Graha Mandiri. Target yang ingin dicapai dari monitoring ini adalah untuk mengkonfirmasi seluruh tahapan serta proses dari seluruh kegiatan terkait dengan BUMDES Catu Graha Mandiri tersebut. Apabila ada penemuan yang kurang memuaskan, maka tim pelaksana mendampingi bidang atau aspek yang kurang maksimal tersebut, sehingga tidak menjadi temuan lagi pada saat evaluasi.

\section{Tahap Evaluasi}

Tahap keberlanjutan program merupakan tahap yang dilakukan berdasarkan hasil monitoring dan evaluasi terhadap kegiatan usaha BUMDES Catu Graha Mandiri. Penilaian tahap ini dilakukan oleh tim pelaksana, Ketua BUMDES, dan LP2M. Dalam rangka keberlanjutan program ini, maka setiap kelompok usaha harus meningkatkan produktivitasnya serta mengajar kelompok usaha yang sejenis atau pun berbeda. Tujuannya agar kelompok lain atau subak lain mendapatkan pengetahuan yang sama, sehingga PKM BUMDES

Catu Graha Mandiri dirasakan manfaatnya oleh semua anggota masyarakat Desa Gumbrih. Apabila anggota BUMDES Catu Graha Mandiri serta anggota masyarakat lainnya merasakan manfaat dari PKM - BUMDES Catu Graha Mandiri ini, maka tim pelaksana mengajukan permohonan tahun kedua tentang keberlanjutan program ini. Dengan demikian, masyarakat Desa Gumbrih terus meningkatkan pengetahuan, keterampilan, dan mendapatkan nilai ekonomi, sehingga Desa 
Gumbrih menjadi desa andalan di wilayah Bali Barat.

Partisipasi Mitra Dalam Pelaksanaan

Program

Setiap kelompok usaha BUMDES Catu Graha Mandiri berpartisipasi dalam menyiapkan tempat untuk kegiatan sosialisasi maupun pelatihan program ini. Selain itu, selama sosialisasi dan pelatihan berlangsung konsumsi disediakan oleh kelompok mitra sebagai bentuk kontribusi nyata bahwa program ini sangat mereka butuhkan untuk meningkatkan pemasukannya. Sejak awal pengenalan program PKM - BUMDES Catu Graha Mandiri ini, Kepala Desa Gumbrih, dan Ketua BUMDES Catu Graha Mandiri menyediakan waktu bertemu. Mereka sangat mengharapkan bantuan dosen Universitas Dhyana Pura untuk membina dan melatih anggota masyarakatnya dalam mengembangkan BUMDES Catu Graha Mandiri. Bukti Ketua BUMDES Catu Graha Mandiri, mendukung program Hibah Internal Universitas Dhyana Pura ini diwujudkan melalui penandatanganan surat pernyataan bermeterai. Kepala Desa, Ketua BUMDES Catu Graha Mandiri, mengumpulkan anggotanya di Kantor Kepala Desa untuk mendengarkan sosialisasi dan kemanfaatan dari program Universitas Dhyana Pura tersebut.

Partisipasi Universitas Dhyana Pura

Partisipasi Universitas Dhyana Pura diwujudkan melalui pembuatan MOU antara Rektor dengan Kepala Desa Gumbrih. Partisipasi ini selanjutnya diwujudkan melalui kehadiran Rektor dalam acara pembukaan sosialisasi PKM serta mengutus tenaga ahli manajemen perhotelan, akuntansi, manajemen pariwisata, tenaga informasi teknologi komputer, dan mengizinkan dosen serta 4 orang mahasiswa dari berbagai program studi untuk terlibat pada kegiatan tersebut. Dengan demikian, partisipasi ini menunjukkan kepedulian Universitas Dhyana Pura Bali dalam melaksanakan program dalam meningkatkan ekonomi serta kesejahteraan masyarakat Indonesia, secara khusus masyarakat Desa Wisata Gumbrih.

\section{HASIL DAN PEMBAHASAN}

Kegiatan pelatihan bagi BUMDES Catu Graha Mandiri ditujukan bagi para pengelola usaha-usaha BUMDES Catu Graha Mandiri Desa Gumbrih seperti petani organic, wisata tirta, dan penjualan kopi dimana sosialisasi dan pelatihan dilaksanakan di bulan Oktober 2020 dan dilakukan pendampingan hingga bulan November 2020. Pelatihan dan pendampingan terlaksana sesuai dengan perencanaan yang dibuat. Selain pelathan dan pendampingan, juga diserahkan modem dan printer sebagai perangkat keras yang dapat menunjang pengembangan bentuk-bentuk usaha di BUMDES Catu Graha. Hasil pelaksanaan penerapan kegiatan ini berjalan lancar karena semua pihak yang terkait sangat mendukung dan membantu dalam pelaksanaan kegiatan pelatihan ini. Peserta kegiatan pelatihan Canva yaitu pengelola usaha-usaha pada BUMDES Catu Graha Mandiri juga sangat antusias dalam pelatihan ini, karena mereka mendapatkan materi yang dapat membantu dalam proses pengemasan produk dan jasa usaha-usaha BUMDES Catu Graha Mandiri sampai dengan promosi di media sosial dengan tools yang ada pada aplikasi Canva. Dokumentasi proses pelatihan dapat di lihat pada gambar 4, gambar 5, dan gambar 6.

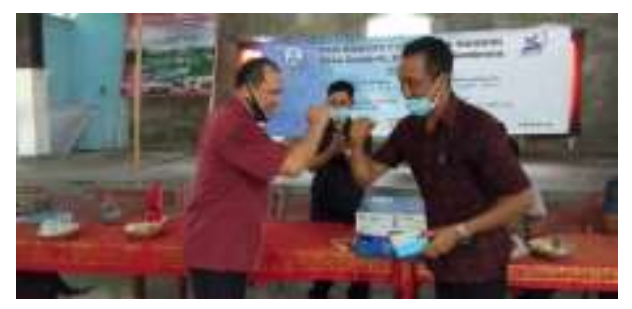

Gambar 4. Ketua PKM Menyerahkan Modem Yang dihibahkan Kepada Perwakilan BUMDES Catu Graha Mandiri 


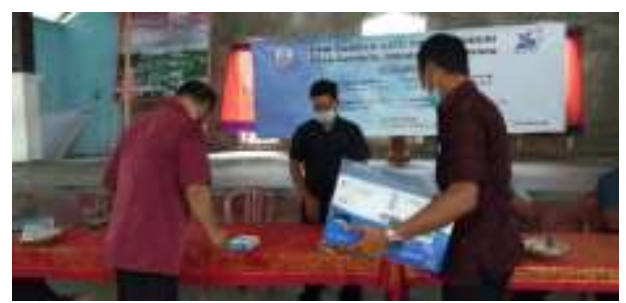

Gambar 5. Ketua PKM Menyerahkan Printer Scan merk EPSON Yang dihibahkan Kepada Perwakilan BUMDES Catu Graha Mandiri.

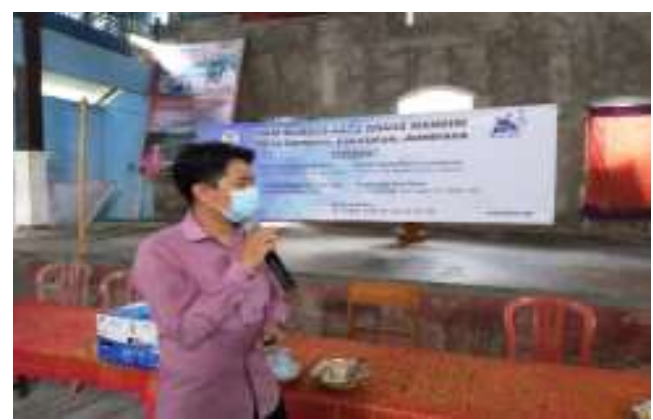

Gambar 6. Proses Pendampingan Pelatihan Penggunaan Tools Canva.

Setelah dilakukan pendampingan dan pelatihan, kemudian 30 peserta, disebarkan kuisioner pemahaman teknologi kembali. Hasil dari kuisioner tersebut, memperlihatkan peningkatan dari rata-rata kuisioner pra-test sebesar 60,7 menjadi rata-rata 97 pada kuisioner post-test.

\begin{tabular}{|l|l|l|}
\hline 1 & 65,7 & 100 \\
\hline 2 & 61 & 100 \\
\hline 3 & 54,3 & 93,3 \\
\hline 4 & 61 & 93,3 \\
\hline 5 & 74,3 & 86,7 \\
\hline 6 & 65,7 & 93,3 \\
\hline 7 & 50 & 98,7 \\
\hline 8 & 50 & 99,6 \\
\hline 9 & 66,7 & 93,3 \\
\hline 10 & 60 & 93,3 \\
\hline 11 & 53,3 & 93,3 \\
\hline 12 & 60 & 93,3 \\
\hline. & & \\
\hline. & & \\
\hline. & & \\
\hline 30 & 56,7 & 96,7 \\
\hline Rata-rata & 60,7 & 97 \\
\hline
\end{tabular}

Tabel 1. Hasil Pra-Test dan Post-Test Pelatihan Canva Pada BUMDES Catu Graha Mandiri

Berdasarkan data pada tabel 1 diatas diketahui adanya peningkatan pemahaman dan pengetahuan dari rata-rata skor 60,7 yang meningkat setelah pelatihan menjadi rata-rata 97. Hasil pra-test dan post-test ini menunjukkan keberhasilan kegiatan pelatihan ini dalam meningkatkan kemampuan dalam menggunakan Canva. Dampaknya sangat positif, dimana para pengelola usaha-usaha BUMDES Catu Graha Mandiri Gumbrih, dapat secara mandiri mempromosikan usaha nya melalui media sosial, baik berupa logo, sampai dengan video kreatif yang dihasilkan melalui aplikasi Canva. Potensi keberlanjutan dari program PKM ini akan dilanjutkan sesuai kebutuhan dan perkembangan luaran-luaran yang dihasilkan mitra, sehingga dapat terus dilakukan monitoring secara berkala.

\section{KESIMPULAN}

Berdasarkan hasil evaluasi pengetahuan dan kemampuan sebelum dan sesudah diadakan pelatihan dan pendampingan penggunaan Canva pada pengelola usaha BUMDES Catu Graha Mandiri kegiatan Program Kemitraan Masyarakat BUMDES Catu Graha Mandiri di Desa Gumbrih yang berlokasi di Desa Wisata Ekotourism Gumbrih, kecamatan Pekutatan, Kabupaten Jembrana, maka dapat disimpulkan bahwa target luaran telah dapat dicapai yaitu peningkatan kemampuan dalam penggunaan teknologi untuk kuantitas, kualitas usaha BUMDES Catu Graha Mandiri Gumbrih termasuk pemasaran usaha menggunakan media sosial.

Dari pelaksanaan kegiatan pengabdian kepada masyarakat tersebut masih ditemukan kendala yang perlu disempurnakan, oleh karena itu perlu diberikan saran baik kepada tim pengelola maupun Pemerintah Desa Gumbrih berikut ini: 1. Pemerintah Desa Gumbrih memberikan arahan regulasi yang jelas bagi kelompok Bumdes sekaligus memberikan 
kesempatan kepada Bumdes untuk melakukan pengelolaan usaha usaha di Desa Gumbrih. 2. Pemerintah Kabupaten Jembrana memberikan konsep bantuan yang jelas dan dapat digunakan oleh kelompok Bumdes khusunya di Desa Gumbrih.

\section{UCAPAN TERIMAKASIH (Bila ada)}

Kami mengucapkan terima kasih Badan Usaha Milik Desa (BUMDES) Catu Graha Mandiri Gumbrih, Kecamatan Pekutatan, Kabupaten Jembrana yang telah menjadi mitra dalam kegiatan program kemitraan masyarakat ini. Kami juga mengucapkan kepada Lembaga Penelitian dan Pengabdian Masyarakat (LPPM) Universitas Dhyana Pura yang telah mendanai program kemitraan masyarakat ini melalui Hibah PKM tahun 2020/2021, dan mahasiswa yang telah membantu sehingga program ini dapat terlaksana dengan baik dan bermanfaat bagi masyarakat.

\section{REFERENSI}

Achmad, Z. A., Azhari, T. Z., Esfandiar, W. N., Nuryaningrum, N., Syifana, A. F. D., \& Cahyaningrum, I. (2020). Pemanfaatan Media Sosial Dalam Pemasaran Produk UMKM. Jurnal Ilmu Komunikasi, 10(1).

Azmi Fadhilah, D., \& Pratiwi, T. (2021). Strategi Pemasaran Produk UMKM Melalui Penerapan Digital Marketing. Coopetition: Jurnal Ilmiah
Manajemen, 12(1). https://doi.org/10.32670/coopetition.v12i1.279

Primadewi, A., Anwar, T. M., Yustin, Y., Sani, A. H., \& Fauzi, M. (2020). Penguatan Pemasaran Produk Umkm Ashfa Madu Borobudur Melalui Strategi Product Branding. Jurnal Pengabdian Kepada Masyarakat, 26(3). https://doi.org/10.24114/jpkm.v26i3.17683

Purwati, Y., \& Perdanawanti, L. (2019a). Pelatihan Desain Menggunakan Aplikasi Canva. Jurnal Pengabdian Mitra Masyarakat (JPMM) Vol., 1(1).

Sholeh, M., Rachmawati, R. Y., \& Susanti, E. (2020). Penggunaan Aplikasi Canva Untuk Membuat Konten Gambar Pada Media Sosial Sebagai Upaya Mempromosikan Hasil Produk Ukm. Selaparang Jurnal Pengabdian Masyarakat Berkemajuan, 4(1). https://doi.org/10.31764/jpmb.v4i1.2983

Widiati, A. (2020). Peranan Kemasan (Packaging) Dalam Meningkatkan Pemasaran Produk Usaha Mikro Kecil Menengah (Umkm) Di "Mas Pack" Terminal Kemasan Pontianak. JAAKFE UNTAN (Jurnal Audit Dan Akuntansi Fakultas Ekonomi Universitas Tanjungpura), $8(2)$. https://doi.org/10.26418/jaakfe.v8i2.40670

Wijaya, M. A. (2020). Efektivitas Komunikasi Pemasaran Digital Pada Produk Umkm Di Masa Pandemi Covid-19. Studi Pustaka. 